\title{
Lignocellulosic Processing with Acid Pretreatment and Enzymatic Hydrolysis for Improving the Acquisition of Sugar Fermentation
}

\author{
Nuniek Hendrianie ${ }^{1}$, Sri Rahmania Juliastuti ${ }^{1}$, Moch. Izati Iwani ${ }^{1}$ \& Affrida Eka ${ }^{1}$ \\ ${ }^{1}$ Department of Chemical Engineering, Sepuluh Nopember Institute of Technology, Indonesia \\ Correspondence: Nuniek Hendrianie, Department of Chemical Engineering, Sepuluh Nopember Institute of \\ Technology, Surabaya 60111, Indonesia. E-mail: nuniek@chem-eng.its.ac.id
}

Received: May 4, 2015

doi:10.5539/mas.v9n7p24
Accepted: June 5, 2015

Online Published: June 30, 2015

\begin{abstract}
Banana peels is a waste which has not been widely used, so that the relatively long time the existence of such waste brings its own problems such as pollution. Banana peels contain high enough lignocellulosic and can be degraded into simpler forms. The Lignin content of banana peels needs to be removed / destroyed structure. The purpose of this study was to determine the effect of the addition ratio of Trichoderma reseei and Aspergillus niger on hydrolysis liquefaction and saccharification time in stage hydrolysis to glucose produced with the highest glucose parameters. In this study, the method was used to degrade lignin by using sulfuric acid (2\%). Afterward, the cellulose content was changed in liquefaction process. Hydrolysis liquefaction performed using Aspergillus niger and Trichoderma reese $i$ with a mixture ratio of 1: 0, 0:1,1:1 and 1:2. Furthermore, substrate hydrolysis liquefaction saccharification going through the process of hydrolysis to increase glucose levels were formed. Hydrolysis liquefaction aims to change the content of starch in the banana skin into glucose using Saccharomyces cerevisiae as the addition of $20 \%$ (v / v). Hydrolysis process of liquefaction is done by varying the sampling time on day $-3,6$, and 9 . In this study the hydrolysis of liquefaction of banana peels use a mixture of Trichoderma reesei and Aspergillus niger 2:1 at a temperature of $50^{\circ} \mathrm{C}, \mathrm{pH} 5$, and $64 \mathrm{~h}$ for resulted in glucose with the best content was $0.52 \%$. In addition, the results showed that the hydrolysis saccharification with the addition of Saccharomyces cerevisiae glucose levels were highest on day 3 with a temperature of $30^{\circ} \mathrm{C}$ and $\mathrm{pH} 5$, resulting in glucose content to $1.63 \%$.
\end{abstract}

Keywords: banana peels, bioethanol, likuification, saccharification, Aspergillus niger, Trichoderma reseei, Saccharomyces cerevisiae

\section{Introduction}

Cellulose is present in agricultural waste and rarely used. One of the agricultural wastes containing cellulose is a banana skin. Banana (Musa paradisiacal) is a type of tropical fruits are produced in Indonesia. Banana production ranked first in Indonesian agriculture. Banana production continued to increase from 1995 until in 2012, production reached 6 million tons per year.

In Indonesia, in addition to be used directly as fresh fruit, banana fruit processing is also used as a raw material in the food industry. Utilization of large banana for various types of these foods will generate solid waste such as banana peels. The weight of a banana skin reaches $35 \%-40 \%$ of the weight of the fruit. Thus, banana peels will produce solid waste 2 to 2.4 million tons per year. Waste banana skin improper course will pollute the environment because it can increase the acidity of the soil (Asteria and Franky, 2013). The process of converting biomass into sugars can be conducted by lignocellulosic fermentation that can be converted into bioethanol. The process basically consists of two main phases, namely pre-treatment (pre-treatment), as well as the hydrolysis of cellulose and hemicellulose into simple sugars. The content of cellulose of banana peels around $12 \%-18 \%$ (Annynomous, 1978).

In order to compare the processes and microorganisms used in the conversion of lignocellulosic into glucose banana skin, then this research will be carried in various lignocellulosic biomass conversion process in order to obtain the best glucose levels. In this study, conducted pre-treatment process is a chemical process with the addition of sulfuric acid $\left(\mathrm{H}_{2} \mathrm{SO}_{4}\right) 2 \%$ to remove the lignin, reducing the crystallinity of cellulose, and increase the porosity of the material. 
Lignocellulosic pretreatment process :

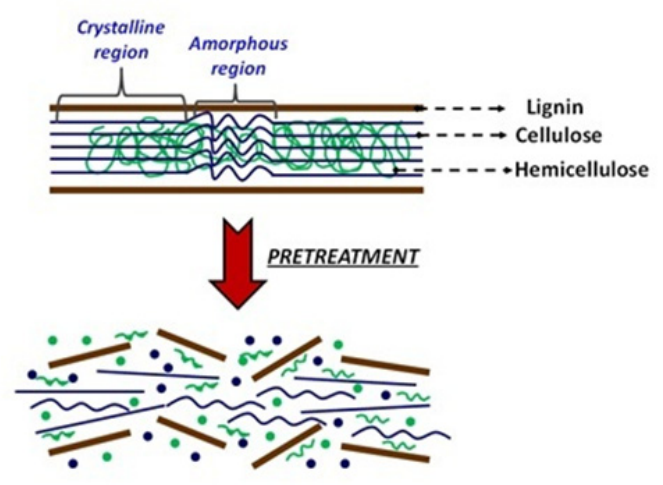

Hydrolysis process comprising the steps of liquefaction and saccharification. Fungus Aspergillus niger used liquefaction and Trichoderma reseei that produce enzymes endogluconase, eksogluconase, and glucosidase to convert cellulose into glucose. Saccharification stage used the yeast Saccharomyces cerevisiae that produces glucoamylase to convert polysaccharides into fermentable sugars (glucose, galactose, mannose, and so on) (Fitria and Yulinah, 2011). The results of this study aims to convert waste banana skin and increase the value of productivity, resulting in high glucose levels. mechanism of cellulose hydrolysis by cellulase enzymes can be seen in the scheme below

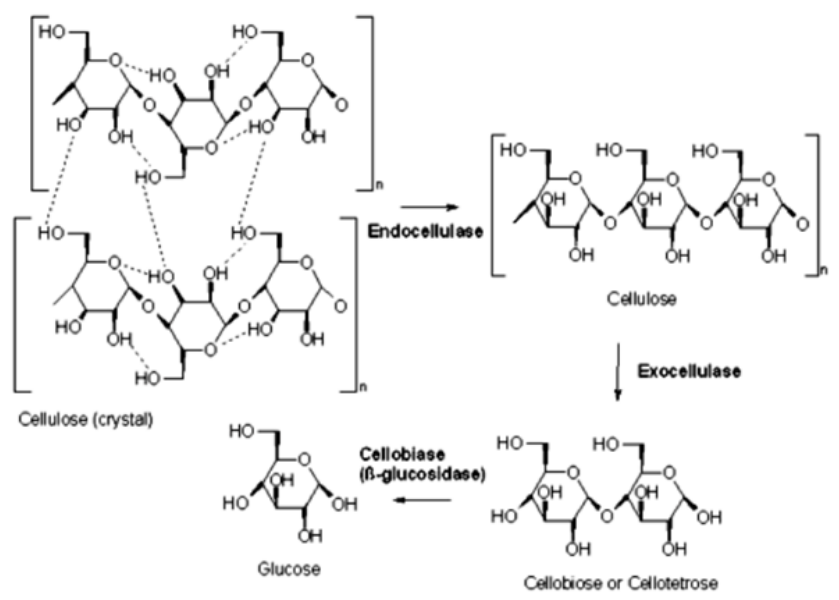

\section{Method}

\section{Lignocellulosic Pretreatment}

The main content of lignocellulosic materials have three different kinds of polymers, namely lignin, hemicellulose, and cellulose. The three components that bond together to form a unified whole. The amount of content of each component depends on the type of biomass, age, and the environment in which the biomass condition, grow, and develop (Jorgensen et al., 2007).

Pretreatment of lignocellulosic biomass to be done to get the result of high glucose. The purpose of the pretreatment is to open the lignocellulosic structure to cellulose becomes more accessible to the enzymes that break down polysaccharides into monomeric sugars polymer. Chemical pretreatment for Banana peels using different chemicals such as acids, alkalis and oxidizing the peroxide and ozone. Among these methods, using a dilute acid pretreatment of $\mathrm{H}_{2} \mathrm{SO}_{4}$ is the most widely used method. Alkaline pretreatment, ozonolysis, and oxidation pretreatments peroxide can be effective in the removal of lignin whereas dilute acid pretreatment is more efficient in the solubilization of hemicellulose (Sun and Cheng, 2002).In this study, pretreatment of lignocellulosic is done by mixing banana peel as much 25 gram with $\mathrm{H}_{2} \mathrm{SO}_{4} 2 \%$ as $420 \mathrm{ml}$ and $\mathrm{NaOH} 6 \mathrm{M}$ as 30 $\mathrm{ml}$, this process is operated at a temperature $30^{\circ} \mathrm{C}, \mathrm{pH} 4-5$, and stirred for 7 hours. Further suspension of banana peel is neutralized with $30 \mathrm{ml}$ of $6 \mathrm{M} \mathrm{NaOH}$ and added $50 \mathrm{~mL}$ of $0.1 \mathrm{M}$ acetate buffer $(\mathrm{pH})$. 


\section{Enzymatic Hydrolysis}

Enzymatic hydrolysis is a process of solving polysaccharides in lignocellulosic biomass, namely cellulose and hemicellulose into its constituent sugar monomers by using enzymes produced by microorganisms. Enzymatic hydrolysis has several advantages, among others, is not the result of hydrolysis of sugar degradation, lower process conditions (low temperatures), has the potential to provide high yields and relatively low maintenance costs of equipment because no corrosive material. Some drawbacks of enzymatic hydrolysis include requiring a longer time and the action of the enzyme is inhibited by the product.

Enzymatic hydrolysis process in this study consists of two stages, namely the stage of liquefaction and saccharification. In the first stage liquefaction hydrolysis by Trichoderma reesei and the addition of microorganism Aspergillus niger to change the content of cellulose into glucose in the banana peel. Aspergillus niger is a fungus that common to hydrolyze cellulose. These microorganisms produce high $\beta$-glucosidase but low endo- $\beta$-1.4-glucanase and exo- $\beta-1,4$-glukanasenya. Trichoderma reesei produces endoglukanase and eksoglukanase to $80 \%$ but lower $\beta$-glukosidase (Ahmed and Vermette, 2008). In this study, liquefaction hydrolysis process is done by varying the ratio of the addition of microorganisms between A.niger: T.reesei 1: 0 , $0: 1,1: 1$ and 1:2. Liquefaction Hydrolysis is done by adding the various appropriate microorganism suspension on banana peels result of pretreatment. Then insert the suspension into the reactor water bath for 64 hours at $50^{\circ}$ $\mathrm{C}$ and a stirring speed of $75 \mathrm{rpm}$. After that, perform glucose analysis method luff schoorl and continue the suspension with the highest glucose levels through saccharification hydrolysis stage.

Saccharification Hydrolysis phase takes place yeast Saccharomyces cerevisisae that can produce glucoamylase. This enzyme can change the content of starch in the banana skin to glucose, resulting in a more reduced sugar. Saccharification Hydrolysis of Saccharomyces cerevisisae is done by adding as much as $10 \%(\mathrm{v} / \mathrm{v})$, then do the aeration at $30^{\circ} \mathrm{C}$ up to 9 days. Furthermore perform sampling on days 3, 6 , and 9 to determine the optimum time required in the process of saccharification hydrolysis

\section{Results}

In this study, firstly kepok banana peels were crushed and roasted to reduce its water contained. Furthermore they were pounded in order to bring out its flours. This reduction size treatment is called the mechanical preparation. It can lead to breakdown the long polymer chain becomes shorter polymer chains and increase its amorphous region, thereby it is able to reduce the degree of crystallinity. Furthermore, these flour was analyzed for levels of lignin, cellulose, and hemicellulose by doing Cheson method.

\subsection{Effect of Acid Pretreatment Levels Against Lignin, Cellulose and Hemicellulose}

This pretreatment was conducted by adding sulfuric acid $2 \%(\mathrm{v} / \mathrm{v})$ which aims to reduce lignin content of banana peels

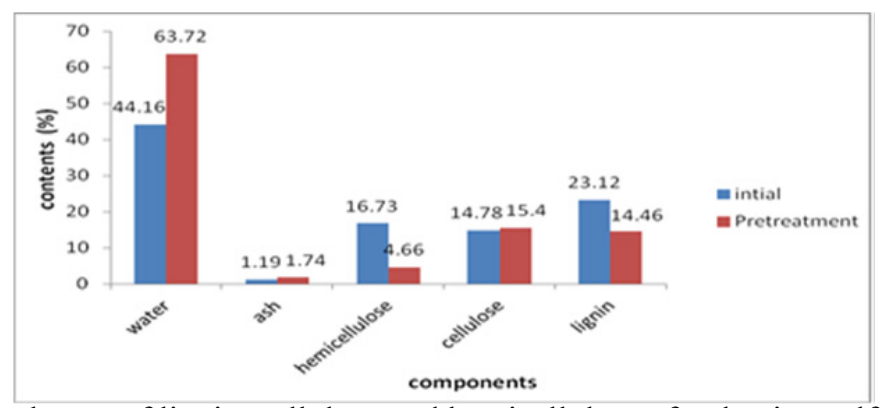

Figure 1. The change of lignin, cellulose and hemicellulose after having sulfuric acid

Figure 1. shows that sulfuric acid $\mathrm{H}_{2} \mathrm{SO}_{4} 2 \%(\mathrm{v} / \mathrm{v})$ addition can decrease lignin content and on the other hand it can enhance celluse content of banana peels. Because of lignin is component for protecting celluse, therefore by crushing this lignin lead the celluse content increase directly. Meanwhile the hemicelluse decrease simultanieously as a class of carbohydrates that are not soluble in boiling water but it can be dissolved in soluble alkali and destroyed in dilute acid.

\subsection{The Effect of Variation of Microorganism Addition in Liquefaction Hydrolysis}

Liquefaction hydrolysis process completed by addition of both Aspergillus niger and Trichoderma reseei were intended to hydrolysis celluse components of banana peels into glucose. Likuification hydrolysis was carried out with the ratio of 1:0; 0:1; 1:1 and 1:2 (v/v) for Aspergillus niger: Trichoderma reseei. 

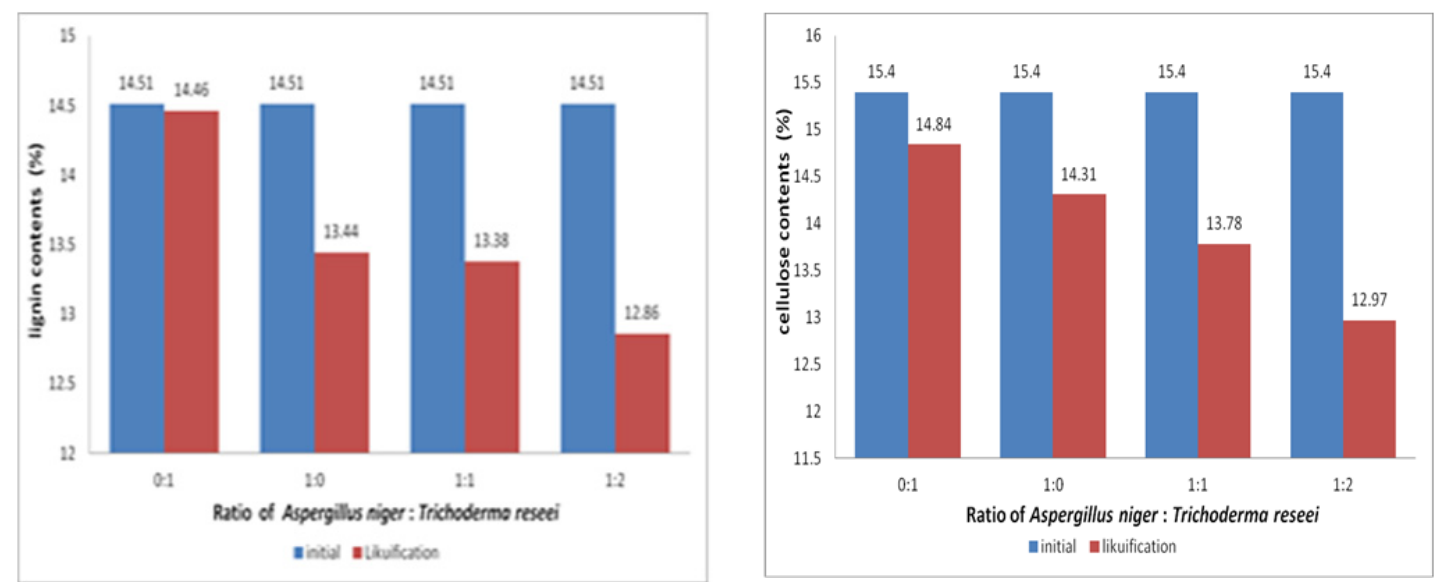

Figure 2. The results of (a) lignin (b) cellulose component in 4 variables of either Aspergillus niger or Trichoderma reseei addition

Figure 2(a) shows that the ratio of 1:2 lignin can be degraded much greater by $12.86 \%$ since having more comparison of Trichoderma reseei, both of these microorganisms can work synergistically to decrease lignin contents by the percent decrease of $11.37 \%$.

Figure 2(b) shows a decrease in cellulose as it has been hydrolyzed into glucose. Through the ratio of 0: 1 (Aspergillus niger: Trichoderma reseei) showed that the reduction percentage of cellulose content is not too significant. It is caused by the usage of Trichoderma reseei during the hydrolysis process has a low specific activity of cellulase enzymes hence it only produced cellulose content by $14.84 \%$. Whereas the ratio of 1: 0 (Aspergillus niger: Trichoderma reseei) showed significantly a decreased level of cellulose about $14.31 \%$, it was due to the use of Aspergillus niger moved the cellulase enzymes containing such of $\beta$-glucosidase. These enzymes work extremely well and selectively to hydrolyze cellulose to glucose in the amorphous region. Amorphous regions in cellulose is an area having a sprawl structure and irregular so it's easier to be hydrolyzed by the enzyme produced by microorganisms. Moreover the mixture ratio of both 1:1 and 1:2 (Aspergillus niger: Trichoderma reseei) kept in a decrease of cellulose percentage, respectively for $10.78 \%$ and $16.04 \%$ where these two value were greater than the previous two variables. It occurred since this combination of the two fungi can utilize the cellulose components having cristallyn character to transform into amorphous cellulose which is easier to be hydrolyzed. The greatest reduction of cellulose occurred through entering either of Aspergillus niger or Trichoderma reseei with a ratio of 1: 2 result in the cellulose contents about $12.97 \%$. This is caused by the usage of Trichoderma reseei which produces either endoglucanase or eksoglucanase enzymes about up to $80 \%$ to hydrolyze cristallyne cellulose to be more tenuous and easily to be hydrolyzed by the $\beta$-glucosidase enzyme.

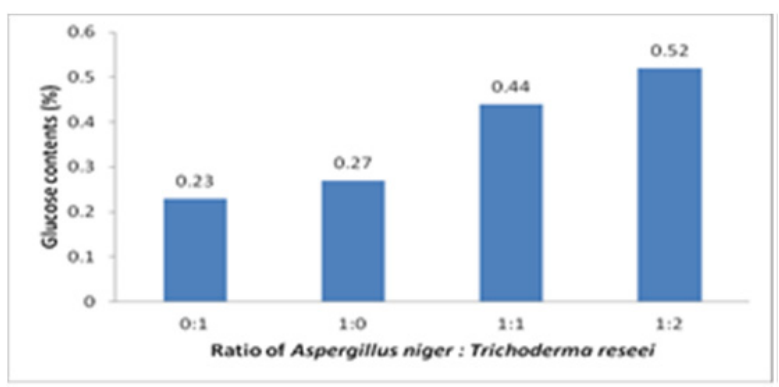

Figure 3. The results of glucose component after having likuification hydrolysis in variables of either Aspergillus niger or Trichoderma reseei addition

Figure 3 shows that the fungal treatment process completed by adding either Aspergilus niger or Trichoderma reseei among those four different variables $(0: 1,1: 0,1: 1$ and 1:2) produce various glucose contents. The best glucose was resulted by including both Aspergillus niger and Trichoderma reseei with the ratio of 1:2. The reducing cellulose indicates that it has been hydrolyzed into glucose by the enzym produced. Endoglucanase has a function to degrade the polysaccharides of cellulose into oligosaccharides (the shorter bond). Meanwhile exoglucanase is used to convert oligosaccharides into unit of disaccharide molecules. The other component is 
$\beta$-glucosidase which serves to convert its unit of disaccharide into two molecules of glucose which is a sugar that can be converted into ethanol. Therefore these three enzyms are able to work for hydrolyzing cellulose to glucose synergistically. By having more combination of Trichoderma reseei, it will accordingly produce more cellobiose. By producing the unit of disaccharide, then it will be converted or brake off by B-glucosidase enzymes more produced by Aspergillus niger into molecule of glucose. Furthermore hemicellulose contain the other units such as xylose, mannose, and galactose, and the bond which connect glucose with other units that can be broken off by Aspergillus niger, therefore the more addition of either Aspergillus niger or Trichoderma reseei the greater glucose produced .

\section{The Effect of Time Variation in Saccharification Hydrolysis Process}

Saccharification Hydrolysis Process was conducted by mixing Saccharomyces cerevisiae with the feed which had resulted by the Liquefaction hydrolysis process with the highest content of glucose.

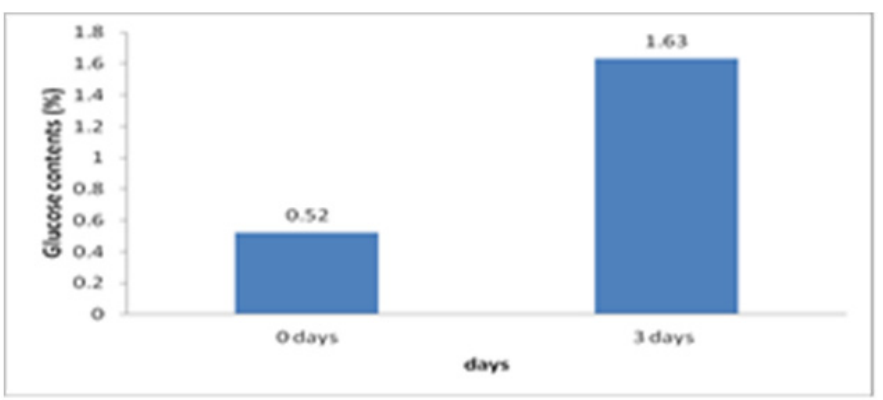

Figure 4. Changes in glucose levels to increase after saccharification hydrolysis of Saccharomyces cerevisiae

Figure 4 depicted that Saccharomyces cerevisiae produced glucoamylase enzym to convert the polysaccharides into fermentable sugars (glucose, galactose, mannose, and so on). Glucoamylase enzym could break the bond of either $\alpha-1.4$ or $\alpha-1.4$ glycosides in the starch molecules into sugar reduction, thus it would enhance the production of reducing sugar. By having the saccharification hydrolysis process, it was seen that Saccharomyces cerevisiae was able to convert the starch of banana peels into a reducing sugar which could be directly fermented into ethanol in the fermentation process. The saccharification hydrolysis was accomplished for 3 days by including Saccharomyces cerevisiae 10\% (v/v), it would increase the level content of glucose by $1.63 \%$.

\section{Discussion}

The addition of variable Aspergillus niger and Trichoderma reseei with a ratio of $1: 2$ at $50^{\circ} \mathrm{C}$ and $\mathrm{pH} 5$ for 64 hours produced the highest glucose by $0,52 \%$ during the process of liquefaction hydrolysis.

The addition of Saccaromyces cerevisiae $10 \%(\mathrm{v} / \mathrm{v})$ in saccharification hydrolysis at $30^{\circ} \mathrm{C}$ dan $\mathrm{pH} 5$ could enhance the level of glucose by $1,63 \%$.

\section{References}

Ahamed, A. P. V. (2008). Culture-based Strategies to Enhance Cellulase Enzyme Production from Trichoderma reesei RUT-C30 in Bioreactor Culture Conditions. Biochemical Engineering Journal, 40, 399-407. http://dx.doi.org/10.1016/j.bej.2007.11.030

Anynomous. (1978). Statistika Indonesia. Biro Pusat Statistika, Jakarta.

Asteria, A. S., \& Franky, A. (2013). Pembuatan Etanol dari Kulit Pisang Secara Fermentasi. Jurnal Teknologi Kimia dan Industri, 2(2), 177-180.

Eugene, W. N., Marie, G., \& John, G. K. (1978). Experiment in Microbiology, International edition,. Holt, Rinehart and Winston.

Fitria, M., \& Yulinah, T. (2011). Produksi Bioetanol Dari Eceng Gondok (Eichhornia crassipes) dengan Zymomonas mobilis dan Sccharomyces cerevisiae, Prosiding Seminar Nasional Manajemen Teknologi XIII

Gerard, J. T., Berdellm, R. F., \& Christine, L. C. (2010). Microbiology An Introduction (10th ed). San Fransisco. Pearson Education, Inc

Harold, J. B. (2002). Microbiological Applications Laboratory Manual in general Microbiology (8th ed). Mc GRAW HILL.

Michael, J., Waites, N. L., Morgan, J. S. R., \& Gary, H. (2001). Industrial Microbiology An Introduction, Blackwelln Wissenschafts. 
Stanbury, P. F., Whitaker, A., \& Hali, S. J. (2000). Principle of Fermentation Technology (2nd ed).

\section{Copyrights}

Copyright for this article is retained by the author(s), with first publication rights granted to the journal.

This is an open-access article distributed under the terms and conditions of the Creative Commons Attribution license (http://creativecommons.org/licenses/by/3.0/). 